\title{
News Report: A Blended Extensive Reading and Intensive Reading Activity
}

\author{
Dung Thi Thanh Do ${ }^{1}$ \\ ${ }^{1}$ Hanoi Pedagogical University 2 \\ E-mail: ${ }^{1}$ thanhdungdo90@gmail.com
}

Received: 23 October 2017; Revised: 1 November 2017; Accepted: 1 November 2017

\begin{abstract}
Abstrack
Reading plays an important role in widening knowledge and learning languages, but it is also a challenge. Although Vietnamese learners often get higher marks in English reading tests in comparison to other skills, students' low motivation to read and their lack of general background knowledge are obvious. This presentation introduces News Report, a blended Extensive Reading - Intensive Reading activity. The process is consisted of four stages: choosing news, summarizing, making a glossary and presenting. The activity is designed with an aim of establishing the reading habit for learners to widen their knowledge and learn the target language simultaneously. As observed, it is unlikely to formulate the reading habit this way but it helps to guide students how to read effectively on their own. Participants will learn a multi-purpose reading activity and know how to apply it on their own or in their classroom .
\end{abstract}

Key words: reading skills; extensive reading; intensive reading; news report;

\section{Introduction}

The best way to improve your knowledge of a foreign language is to go and live among its speakers. The next best way is to read extensively in it (Nuttall, 1996)

Reading is an activity that can add someone's knowledge about important news and also some new vocabulary items and grammatical patterns. Two prevalent kinds of teaching reading are Extensive and Intensive. Before compared and contrasted, definition and characteristics of each teaching methodology are presented. A combined methodology of teaching reading is suggested in the end.

IR is the most typically taught method of teaching reading. According to Long and Richards (1987), Intensive Reading is a detailed in-class analysis, led by the teacher, of vocabulary and grammar points, in a short passage. Unlike Extensive Reading, this kind calls attention to grammatical forms, discourse markers, and other surface structure details for the purpose of understanding literal meaning, implications, rhetorical relationships, and the like. (Brown, 1989). Most often all the students read the same short text that the teacher decides.

Some main features of Intensive Reading are listed below. (1) usually classroom based (2) reader is intensely involved in 
looking inside the text, (3) students focus on linguistic or semantic details of a reading (4) students focus on surface structure details such as grammar and discourse markers, (5) students identify key vocabulary, (6) students may draw pictures to aid them (such as in problem solving), (7) texts are read carefully and thoroughly, again and again, (8) aim is to build more language knowledge rather than simply practice the skill of reading, (9) seen more commonly than extensive reading in classrooms.

The advantage of IR is that it focuses the learner on certain aspects of the language such as structure, vocabulary and idioms. By that way, it provides a base for students to develop a greater control of language. Brown (2007) sees intensive reading classes as a place where bottom-up and top-down processing are used interactively to achieve reading comprehension. In detailed, attention should be given to phoneme, root and word recognition to progress toward meaning (bottom-up) as well as to the (topdown) process of starting with background knowledge and general meaning and working from there to more specific comprehension.

While there are proven benefits to an intensive reading methodology, researchers have also cited some negatives. In a class with multireading abilities, students may not be able to read at their own level because everyone in the class is reading the same material. Moreover, the text may or may not interest the reader because it is chosen by the teacher. That might explain for students' complaint, which is reading in English is difficult or boring. Besides, exercises and assessment usually follow intensive reading, students may come to associate reading with testing and not pleasure.

Long and Richards (1971) identify extensive reading as "occurring when students read large amounts of high interest material, usually out of class, concentrating on meaning, "reading for gist" and skipping unknown words." Sharing the same view, Brown (1989) explains that extensive reading is carried out "to achieve a general understanding of a text." In other words, this reading type is always done for the comprehension of main ideas, not for specific details. Other major aim of extensive reading is to build reader confidence and enjoyment (Bamford).
Day and Bamford (1980) put forward ten characteristics identified in successful Extensive Reading Programs as below (1) Students read as much as possible, (2) A variety of materials on a range of topics is available, (3) Students select what they want to read, (4) The purposes of reading are usually related to pleasure, information and general understanding, (5) Reading is its own reward. (6) Reading materials are well within the linguistic competence of the students in terms of vocabulary and grammar, (7) Reading is individual and silent. (8) Reading speed is usually faster than slower. (9) Teachers orient students to the goals of the program. (10) The teacher is a role model of a reader for the students.

There are many reasons why Extensive Reading is good for language development. First, ER allows students to meet the language in its natural context and see how it works in extended discourse beyond the language met in textbooks. By that way, new vocabulary and grammar points may be acquired even though they are not directly taught. Obviously, textbooks and other study materials introduce language patterns but reading in a variety of contexts helps to facilitate a deep understanding of how the patterns work. More importantly, this kind of reading builds confidence, motivation, enjoyment and a love of reading which makes students more effective language users Krashen (1993a). Last but not least, ER builds background knowledge in many fields that could prepare students for future work.

Some challenges of Extensive Reading are obvious. Students are advised to choose texts within their language proficiency level. For the first days of practice, it can be very timeconsuming for teachers to read each student's journals and reports. More seriously, students who have only been exposed to Intensive Reading programs may not believe that Extensive Reading is a "proper" way to learn. They might feel that time spent on Extensive Reading will take away from time that could be spent on learning language skills.

It is like the difference between 'learning to read' and 'reading to learn'. Intensive Reading introduces new language items to the students, while Extensive Reading helps the students practice and get a deeper knowledge of them. Both are necessary. (Day \& Bamford, 1998)

As described above, extensive reading is 
sometimes described as in opposition to intensive reading (Susser, Robb 1990) and sometimes described as complimentary to intensive reading, but used for different purposes (Renandya, Jacobs 2002). As a result of these revisions, current best practices in EFL teaching now assume a balanced approach of intensive and extensive reading. Harmer (2007) states that To get maximum benefit from their reading, students need to be involved in both extensive and intensive reading. This view is advocated by Brown (2007) an extensive reading component in conjunction with other focused reading instruction is highly warranted and also by Anderson (1999) what makes the reader a good reader is that he/she has developed the strategies and skills through intensive reading that are transferred to extensive reading contexts.

\section{Material and Methods}

Objectives: Students read newspapers to get information to enhance their background knowledge and to enjoy reading, create a reading habit.

Students choose recent news which are of their interest and within or slightly beyond their English proficiency from free online sources. They are recommended to avoid news which are consisted of many new words/patterns (more than $5 \%$ ) so that they can read for gist without being demotivated because of vocabulary barrier. Bell (1998) argues that frequent use of dictionary will cause inefficient reading and destroy the pleasure that reading is intended to provide. Graham Stanley from British Council, Barcelona suggests that by avoiding dictionary, the students are expected to be encouraged to jot down the words they come across in a vocabulary notebook and they can look them up after they have finished reading. It will make the students guess the meaning based on the context instead. In addition, students should also be free, indeed encouraged, to stop reading anything that isn't interesting or which they find too difficult. Although reading challenging texts has been proven to be a motivating or competitive factor in some cases, in others it becomes counter-productive if students try to read texts that are more difficult than they can manage and consequently become discouraged.

Below websites are suggested to choose appropriate reading texts:

http://www.english-online.at/index.htm

http://www.bbc.com/

http://www.abc.net.au/news/

http://edition.cnn.com/

http://english.vietnamnet.vn/

http://english.vov.vn/

\section{Results and Discussion \\ Out-of-class work}

Students choose appropriate reading materials and read for gist. Allowing students to select what they want to read is the key to this method. Students are more likely to read materials in which they are interested. This makes sense for them to choose what (and where and when) to read. After that, they need to note down 3-5 new words/patterns, write a summary of the text and give their own opinion over the issue. Writing summary is not an easy thing to do. It allows learners to assert full control, both of the main factual or fictional content of an article/ book, and of the grammar and vocabulary used to express it (Bell, 1998).

\section{In-class work}

Each week, three students make a short presentation on the news they have read. They are required to summarize the text and give their viewpoints on the topic. By doing short presentation, the students will have knowledge of the right preparation, self- independence and autonomy (Bell, 1998). Unlike Intensive Reading, they do not have to answer some questions related to the topic which is given by the teacher, which are available on the text, so that the students only rewrite it. Obviously, making a short presentation is also a tough task which might discourage students from reading pleasantly. However, to students in Vietnam context, the principle of learners being responsible for their own learning and reading for themselves is not applicable. In this case, an oral report with formal assessment makes sure to maintain students' reading habit. Hitosugi and Day observe that students who have not done their reading felt left out and this motivates them to read. They see performing the activities in class as a way how to show students 
that ER is an integral part of their course. Students' presentations of their personal readings are valuable in terms of strengthening the class as a language-learning community. In other words, this Extensive Reading activity which combined with writing or combined with speaking practice in a meaningful way helps to improve overall language skills.

\section{Teacher roles}

Teachers orient and guide their students how to choose the right materials. For the first weeks, they may assist in selecting appropriate reading material that will be interesting as well as easy. Teachers can make a sample report of the news they read so that students understand how things work and what to do in their turn. Students need to know that student's personal experiences of what they read e.g. whether they found the material enjoyable or interesting and why, whether they can learn anything in language or knowledge from the text that matters. Teachers are highly recommended to give feedback to acknowledge students' efforts. Teachers' constructive feedback is an invaluable source of motivation for students. Furthermore, the teacher is a role model of a reader. Particularly with teenagers, discussion of shared book experiences can provide a neutral ground where communication in English can take place easily and naturally (Bell, 1998).

\section{Conclusion}

In summary, by doing a series of activities in both extensive and intensive sense, students are supposed to broaden their background knowledge and reading skills. These kinds of activities such as summarizing and reporting will encourage students to explore their abilities and make reading no longer boring. It cannot be denied that introducing Extensive reading into ELT teaching places means more demands on teachers and students but the results are certainly worth the effort.

\section{Suggestion}

This research is the first research big hope the next researcher can to do this better.

\section{References}

Anderson, N. (1999). Exploring Second Language Reading; Issues and Strategies, 59. Newbury House Teacher Development.

Bell, T. (2001). Extensive Reading Speed and Comprehension. The Reading Matrix, retrieved from ht t p:// www.readingmatrix.com/articles/bell/ index.html

Brown, H. D. (1987). Principles of language learning and teaching ( $3 r d$ ed). USA: Pearson Education.

Brown, H.D. (2007). Teaching by Principles, An Interactive Approach to Language Pedagogy, Third Edition. 360; 366-367. Pearson-Longman.

Day, R. and Bamford, J. (1998). Extensive Reading in the Second Language Classroom, Cambridge University Press.

Day, R. and Bamford, J. (2004). Extensive Reading Activities for Teaching Language, Cambridge University Press.

Krashen, S. D. (1993a). The power of reading: Insight from the research. Englewood. CO: Libraries Unlimited, INC

Harmer, J. (2007). The Practice of English Language Teaching, Fourth Edition, 283. Pearson-Longman,

Long M.H \& Richards, J.C. (1987). Methodology in TESOL. USA: Heinle\&Heinle.

Nuttal, C. (1996) Teaching Reading Skills in a Foreign Language; New Edition, 127. Heinemann. Psychology. 56: 9-14. 